\title{
A Prospective, Randomized, Placebo-Controlled Study to Identify Biomarkers Associated with Active Treatment in Psoriatic Arthritis: Effects of Adalimumab Treatment on Lesional and Nonlesional Skin
}

\author{
Marjan de Groot ${ }^{\mathrm{a}}$ Daisy l. Picavet ${ }^{\mathrm{a}}$ Arno W.R. van Kuijk ${ }^{\mathrm{b}}$ Paul P. Tak $^{\mathrm{b}}$ Jan D. Bos ${ }^{\mathrm{a}}$ \\ Menno A. de Rie ${ }^{a}$ Marcel B.M. Teunissen ${ }^{a}$ \\ Departments of ${ }^{a}$ Dermatology and ${ }^{b}$ Clinical Immunology and Rheumatology, Academic Medical Center, \\ University of Amsterdam, Amsterdam, The Netherlands
}

\section{Key Words}

Adalimumab - Psoriasis - Psoriatic arthritis - Biomarkers • Innate immunity

\begin{abstract}
Background: There is a need for biomarkers to screen the effectiveness of (novel) therapeutic agents for psoriasis at an early stage. Objective: We aimed to determine which of the changes in psoriatic skin correlates best with clinical improvement 4 weeks after effective adalimumab therapy. Methods: Twenty-two psoriatic arthritis patients were randomized to receive adalimumab or placebo. T cell numbers and markers of innate immunity were estimated in lesional and nonlesional skin biopsies at baseline and after 4 weeks of treatment. Results: CD161+ and elastase+ dermal cells in lesional skin were significantly reduced upon 4 weeks of successful adalimumab treatment compared with placebo. Conclusion: Early improvement of psoriasis lesions during adalimumab therapy is associated with a marked reduction of infiltrated dermal CD161+ T cells and elastase+ neutrophils, suggesting that these parameters could be used as biomarkers to monitor early changes after active treatment in small proof-of-concept studies of short duration.
\end{abstract}

Copyright $\odot 2012$ S. Karger AG, Basel

\section{KARGER}

E-Mail karger@karger.com

www.karger.com/drm

\section{Introduction}

Because skin is the primary site for inflammation in psoriasis, and the tissue is easy to obtain, serial skin biopsies are commonly used to evaluate the effects of novel treatment modalities for psoriasis [1-5]. The rapid increase in the development of numerous new, targeted therapies clearly raises the need for sensitive biomarkers, which can be used for selection purposes as early as possible during the development process. Several hypotheses on the pathogenesis of psoriasis have been proposed over the years, varying from keratinocyte-centered to T cellmediated to aggravation at the level of innate immunity [6]. The latter is based on observations that many cellular and humoral elements of the innate immune system in lesional and nonlesional psoriatic skin are activated or increased [7-16], as well as on the remarkable improvements seen in clinical trials with antagonists of tumor necrosis factor (TNF)- $\alpha$ [17-20], which is a key cytokine of the innate immune response. Recently, we showed a reduction of different inflammatory cell types of the innate immune system in psoriatic skin during etanercept treatment [21]. 
The primary objective of this study was to investigate early changes in lesional and nonlesional skin from psoriatic arthritis patients, parallel to the clinical response to adalimumab - a known effective biological to block TNF- $\alpha[17,22,23]$ - in order to identify sensitive biomarkers that may facilitate determination of the effectiveness of novel agents to treat psoriasis at a premature stage. The effect of adalimumab therapy on synovial tissue in these patients has been published elsewhere [24]. In this randomized, placebo-controlled study, we assessed the immunohistological changes in the skin, together with clinical changes that occurred between baseline and 4 weeks of treatment with either adalimumab or placebo. We focused on changes in numbers of $\mathrm{T}$ cells (CD3) and several markers of the innate immune system (CD68, CD161, elastase, TNF- $\alpha$, BDCA-2).

\section{Methods}

\section{Patients}

Twenty-four patients with active psoriatic arthritis were enrolled into a randomized double-blind, placebo-controlled, single-center study performed at the Academic Medical Center of the University of Amsterdam [24]. The study protocol was reviewed and approved by the medical ethical committee and all patients gave their written informed consent before enrolment. The study was conducted according to the Declaration of Helsinki principles. The diagnosis of psoriatic arthritis was estimated at least 3 months prior to baseline and all patients had to have active disease (at least 2 swollen and 2 tender joints) at the time of enrolment. Further clinical assessments of the joints by a rheumatologist have been described in detail elsewhere [24]. Twenty-two of the patients suffered from active psoriatic skin lesions as diagnosed by a dermatologist, whereas the other 2 had a documented history of psoriasis but no active lesions at baseline.

Patients were allowed to use concomitant methotrexate; however, to minimize the impact of this drug on our study, the methotrexate-receiving patients had to be stable for at least 28 days. Patients were not allowed to use any other disease-modifying anti-rheumatic drug 1 month prior to baseline. Use of nonsteroidal anti-inflammatory drugs was allowed, provided that the dose had been stable for at least 28 days. Parenteral, intra-articular or oral use of corticosteroids within 28 days before enrolment into the study was not allowed. Topical treatments for psoriasis were not allowed 14 days prior to baseline, with the exception of low potency (class I) topical steroids to be used on scalp, palms, groin and/or soles of feet only, and emollients. Other exclusion criteria were the use of any biological agent or investigational drug within the previous 6 months and having a history of tuberculosis or a malignancy in the past 10 years. Infection with HIV, hepatitis B or $\mathrm{C}$ virus was excluded via serological testing. Patients with another serious infection within 4 weeks before baseline, or a significant history of cardiac, renal, neurological or metabolic disease were excluded from the study. Pregnant or breastfeeding patients were not allowed to enter the study.

Biomarkers Associated with Active Treatment in Psoriatic Arthritis

\section{Treatment}

Patients were randomized in a 1:1 ratio to receive a subcutaneous injection with either adalimumab $40 \mathrm{mg}$ or matching placebo at baseline and a second injection 2 weeks later.

\section{Skin Biopsies}

In each patient 4-mm punch biopsies were taken from lesional and nonlesional skin, preferentially from non-sun-exposed areas, at baseline and at week 4 . The first and second biopsies were taken from the same target psoriatic plaque, separated by at least $1 \mathrm{~cm}$. The biopsy samples were randomly coded, snap-frozen in Tissue-Tek OCT compound (Sakura Finetek Europe, Zoeterwoude, The Netherlands) by immersion in liquid nitrogen and stored at $-80^{\circ} \mathrm{C}$ until processing. Five-micrometer cryostat sections were cut and mounted on glass slides before being stored at $-80^{\circ} \mathrm{C}$ until immunohistochemical staining. For each staining three sections of each biopsy were analyzed to minimize random variation.

\section{Immunohistochemical Analysis}

We used the following antibodies to stain serial skin sections: FITC-conjugated anti-CD3 (BD Pharmingen, San Jose, Calif., USA) to identify T cells, anti-CD68 (clone EBM11; Dako, Glostrup, Denmark) to identify macrophages, anti-human neutrophil elastase (Dako), anti-CD161 (BD Pharmingen) to stain for NK-T cells and Th17 cells, anti-TNF- $\alpha$ (Monosan, Uden, The Netherlands) and FITC-conjugated anti-BDCA-2 (Miltenyi Biotec $\mathrm{GmbH}$, Bergisch Gladbach, Germany) to identify plasmacytoid dendritic cells. A horseradish peroxidase (HRP)-conjugated polyclonal rabbit anti-human von Willebrand factor (Dako) antibody was used in double staining with TNF- $\alpha$ to distinguish TNF- $\alpha$-expressing endothelial cells from other TNF- $\alpha$-positive cells.

Following incubation with FITC-conjugated antibodies to CD3 and BDCA-2, sections were successively incubated with rabbit anti-FITC (Dako) and HRP-conjugated goat anti-rabbit immunoglobulins (Dako). Following incubation with antibodies to CD68, elastase and TNF- $\alpha$, the sections were incubated with biotin-conjugated goat anti-mouse immunoglobulins and next with HRP-conjugated streptavidin (Dako). After anti-CD161, the sections were incubated with goat anti-mouse immunoglobulins and then with the alkaline phosphatase (AP) mouse anti-AP kit from Dako. The signal of the elastase, CD68, TNF- $\alpha$ and BDCA2 stainings were enhanced with the tyramide signal amplification system (Perkin Elmer, Mass., USA). The color development was achieved with Fast Red (Dako) for the CD161 staining, and for the other stainings we used an amino-ethylcarbazole kit from Vector (Brunschwig Chemie, The Netherlands). In the case of TNF- $\alpha$ double staining, anti-TNF- $\alpha$ was tagged with AP-conjugated streptavidin (Dako), and after using the tyramide signal amplification system, color development was achieved with an AP staining kit (Vector). The single-stained sections were counterstained with Mayer's hematoxylin (Merck, Darmstadt, Germany). After the staining procedure all sections were mounted with Kaiser's glycerol gelatine (Merck).

Twenty high-power fields per section were analyzed by 2 independent observers blinded for order, patient identity and clinical data. The epidermal and dermal regions were separately counted. Positive staining of CD3, CD68, CD161, BDCA-2, elastase and TNF- $\alpha$ was expressed as positive cells per square millimeter. 
Clinical Evaluation

To evaluate the clinical response to the different treatments the Psoriasis Area and Severity Index (PASI) and the Body Surface Area (BSA) were assessed at baseline and at week 4 .

\section{Statistical Analysis}

SPSS for Windows (V 17.0; SPSS, Chicago, Ill., USA) was used for statistical analysis. Baseline characteristics between the two groups were compared using Student's t test for normally distributed data and Mann-Whitney $U$ test for variables with a skewed distribution. Correlations of changes in clinical parameters and immunohistochemical markers were analyzed with Spearman's rank correlation. Additionally, each of the end points was analyzed using an analysis of covariance model (ANCOVA) after rank transformation to correct for baseline differences [25].

\section{Results}

\section{Clinical Results}

The baseline demographic and clinical features of the 22 psoriatic arthritis patients used in this study are specified in table 1. As expected, we found a marked clinical improvement after adalimumab therapy, but, unfortunately, the PASI reduction just missed significance, most likely due to the relatively low PASI at baseline. The mean PASI score after 4 weeks of adalimumab treatment was 2.61 points lower compared to placebo (95\% CI -0.08 to $5.30, \mathrm{p}=0.056$ ). The mean PASI decreased from 5.89 (SD 4.25) to 4.01 (SD 2.49) in the adalimumab group, whereas there was a slight increase in the placebo group from 4.72 (SD 2.55) to 5.45 (SD 4.05). The mean BSA score after 4 weeks of adalimumab treatment was 1.43 points lower compared to placebo $(95 \% \mathrm{CI}-0.71$ to $3.56, \mathrm{p}=0.18)$. In the adalimumab group the mean BSA decreased from 4.88 (SD 3.91) to 3.79 (SD 3.81), whereas there was a slight increase in the placebo group from 3.26 (SD 3.08) to 3.60 (SD 3.53). In all adalimumab-treated patients, clinical improvement was sustained at week 12. In summary, although there was a clear trend of clinical improvement after 4 weeks of adalimumab treatment, there were no statistically significant differences between the adalimumab- and placebo-treated groups with regard to any of the clinical features depicted in table 1.

\section{Immunohistochemical Analysis}

Complete sets of paired pretreatment and posttreatment, lesional and nonlesional skin samples were available from only 18 of the 22 patients. In 3 patients no lesional samples could be obtained due to the localization
Table 1. Demographic and clinical features of 22 patients with psoriatic skin lesions in the different treatment groups

\begin{tabular}{lcc}
\hline & $\begin{array}{c}\text { Adalimumab } \\
(\mathrm{n}=11)\end{array}$ & $\begin{array}{l}\text { Placebo } \\
(\mathrm{n}=11)\end{array}$ \\
\hline Age, years & $43.1(21-61.1)$ & $47.4(25.3-78.4)$ \\
M/F & $8 / 3$ & $6 / 5$ \\
Currently receiving MTX & $6(54.5 \%)$ & $4(36.4 \%)$ \\
MTX dose, mg/week & $17.5(10-25)$ & $20(15-25)$ \\
Duration of psoriasis, years & $6.0(0.4-18.5)$ & $7.4(1.9-18.2)$ \\
Duration of PsA, years & $11.1(0.1-27.7)$ & $18.8(1.9-53.2)$ \\
Baseline PASI & $5.9(1.5-13.8)$ & $4.7(0.7-7.1)$ \\
Baseline BSA & $4.9(0.5-10.6)$ & $3.3(0.3-9.7)$ \\
\hline
\end{tabular}

MTX = Methotrexate; PsA = psoriatic arthritis; PASI = psoriasis area and severity index; BSA = body surface area. of the psoriatic lesions (e.g. scalp, intra-auricular or anal cleft) and in 1 patient we could not dispose of a nonlesional sample at week 4 . The results of the analysis of these 18 complete sets are shown in table 2 . We found that all numbers of epidermal and dermal CD3 and innate immunity markers decreased in lesional skin following adalimumab treatment, with the exception of epidermal CD68+ and TNF- $\alpha+$ cells. In contrast, in the placebo group there was only a reduction of lesional epidermal CD3+ cells and dermal BDCA-2+ cells and these reductions were smaller than in the lesional skin of the adalimumab-treated group. Except for only a minor decrease in the number of epidermal CD161+ cells and dermal elastase+ and TNF- $\alpha+$ cells, adalimumab treatment did not reduce any of the markers in nonlesional skin. There was a negligible reduction of $\mathrm{CD} 3+, \mathrm{CD} 68+, \mathrm{CD} 161+$ and TNF- $\alpha+$ epidermal cells and TNF- $\alpha+$ dermal cells in the nonlesional skin following placebo treatment. Overall, none of the differences between the two treatment groups at baseline, as well as the reduction or increase of any marker after effective treatment, was statistically significant. However, when ANCOVA was applied to correct for the imbalance at baseline, we found that the effect of adalimumab treatment in lesional skin was significant for dermal CD161+ (median reduction 6.9 cells $/ \mathrm{mm}^{2} ; \mathrm{p}=$ 0.046 ) and elastase+ cells (median reduction 9.0 cells/ $\left.\mathrm{mm}^{2} ; \mathrm{p}=0.024\right)$. 
Table 2. Median values of several biomarkers in lesional and nonlesional psoriatic skin before and after treatment with adalimumab

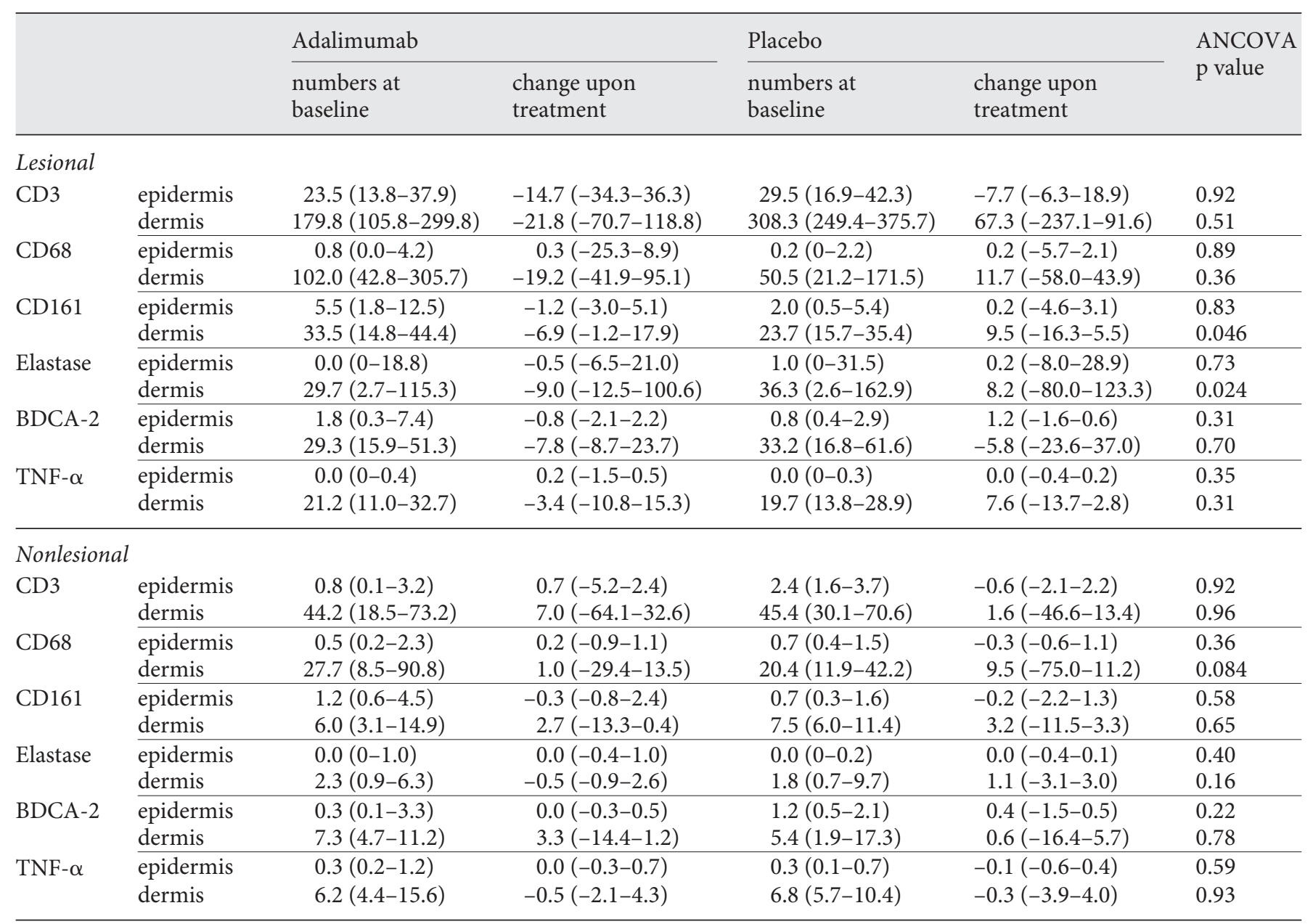

Numbers of CD3+ T cells, CD68+ macrophages, CD161+ NK-T cells, elastase+ neutrophils, BDCA-2+ plasmacytoid dendritic cells and TNF- $\alpha+$ cells in the epidermis and dermis, at baseline or after 4 weeks of treatment with adalimumab or placebo, are expressed as median (range) cells/mm2. A positive or negative value for change represents an increase or decrease in cell numbers, respectively. After ANCOVA was applied to correct for baseline imbalances, the effect of adalimumab versus placebo treatment after 4 weeks was significant only for the reduction in the number of lesional dermal CD161+ $(\mathrm{p}=0.046)$ and elastase + cells $(\mathrm{p}=0.024)$.

Correlation between PASI Reduction and Changes in Psoriatic Skin Lesional and Nonlesional Biomarkers

After applying a Spearman's rank correlation, we found no statistically significant correlation between PASI reduction and changes in cellular markers, which is most likely due to the relatively low PASI at baseline and related lack of significance in PASI reduction upon adalimumab treatment. Yet, there was a trend towards a correlation between improvement in PASI and reduction of elastase+ cells located in the dermis of lesional skin (rho $=0.423, \mathrm{p}=0.071$ ).

Biomarkers Associated with Active Treatment in Psoriatic Arthritis

\section{Discussion}

This placebo-controlled study with adalimumab was conducted to address the question which immunological markers in psoriatic skin could be used as a biomarker to determine at an early stage the clinical efficacy at group level in relatively small studies. In concordance with our parallel study on synovial tissue [24], almost all markers in the present study showed a clear trend (although not significant) of decreased numbers in psoriatic lesional skin in the adalimumab group. However, after applying 
an ANCOVA, a significant reduction of CD161+ and elastase+ cells was demonstrated in the dermis of lesional skin upon 4 weeks of adalimumab treatment. This is in line with our previous investigation, in which we reported the decline of CD161+ and elastase+ cells in psoriatic skin after 3 weeks of treatment with etanercept in psoriasis patients [21]. In contrast to our results, another study on adalimumab treatment in psoriasis could not show a significant reduction of CD161+ cells in the epidermis or dermis after 12 weeks of treatment [26]. However, this is possibly due to the limited number of patients, as only 4 patients were treated with adalimumab in this study and no data were shown regarding the clinical response of each individual patient.

CD161 and elastase are relevant markers for psoriasis. As concerns CD161, this marker is expressed among others by NK-T cells. Activation of NK-T cells results in prompt release of high levels of cytokines like INF- $\gamma$ and TNF- $\alpha$, and NK-T cells have mutual interactions with dendritic cells and keratinocytes, and are thought to have a role in psoriasis $[27,28]$. Furthermore, CD161 is a cell surface marker associated with Th17 cells $[29,30]$, which is a subtype of $\mathrm{T}$ helper cell that is currently recognized to have a pivotal role in the pathogenesis of psoriasis because of the production of IL-17 and IL-22 [31]. In addition to CD161+ cells, elastase+ cells in lesional dermis were also significantly reduced after 4 weeks of treatment with adalimumab. Elastase is a marker of neutrophils [32] and infiltration of neutrophils in the skin, especially in the epidermis, is one of the morphological characteristics of psoriasis [33]. Previous studies showed that elastase correlates well with skin induration [34] and disappears with successful therapy [35]. Furthermore, expression of dermal elastase correlates statistically significantly to PASI [36]. Consistent with our results, a previous study showed a significant reduction of elastase+ cells after etanercept treatment [37].
In contrast to our findings for synovial tissue [24], we did not find a significant correlation between clinical improvement and changes in the cellular markers in the skin. This might be explained by the selection criteria for this study. The psoriatic arthritis patients were primarily included based on the activity of their arthritis rather than the activity of the skin lesions, and this may have caused a relatively low PASI in our patient group. It is known that the severity of the skin disease and the arthritis often do not correlate with each other [38]. This low PASI at baseline is most likely the reason that the PASI reduction upon adalimumab just missed significance (despite the marked clinical improvement), and thereby also hampered to reach significant correlation between the PASI-reduction and the adalimumab-induced decrease in CD161+ and elastase+ dermal cells. Despite the suboptimal conditions for evaluation of the skin, our study nevertheless shows that changes in CD161+ and elastase + cells of psoriatic dermis may be useful biomarkers to screen for effective therapies at an early stage during drug development. Future investigations on biomarkers in psoriatic skin, preferably including patients with a higher PASI at baseline, are necessary in order to confirm and extend our results in studies evaluating (novel) therapeutic agents for psoriasis.

\section{Acknowledgement}

This investigator-initiated study was supported by Abbott B.V., The Netherlands.

\section{Disclosure Statement}

The authors declare no conflicting interests.

\section{References}

1 Goedkoop AY, de Rie MA, Picavet DI, Kraan MC, Dinant HJ, van Kuijk AW, Tak PP, Bos JD, Teunissen MB: Alefacept therapy reduces the effector T-cell population in lesional psoriatic epidermis. Arch Dermatol Res 2004;295:465-473.

2 Goedkoop AY, Kraan MC, Teunissen MB, Picavet DI, de Rie MA, Bos JD, Tak PP: Early effects of tumour necrosis factor alpha blockade on skin and synovial tissue in patients with active psoriasis and psoriatic arthritis. Ann Rheum Dis 2004;63:769-773.
-3 Goedkoop AY, de Rie MA, Teunissen MB, Picavet DI, van der Hall PO, Bos JD, Tak PP, Kraan MC: Digital image analysis for the evaluation of the inflammatory infiltrate in psoriasis. Arch Dermatol Res 2005;297:5159.

4 Gottlieb AB, Chamian F, Masud S, Cardinale I, Abello MV, Lowes MA, Chen F, Magliocco M, Krueger JG: TNF inhibition rapidly down-regulates multiple proinflammatory pathways in psoriasis plaques. J Immunol 2005; 175:2721-2729.

\footnotetext{
5 van Lingen RG, Korver JE, van de Kerkhof PC, Berends MA, van Rens DW, Langewouters AM, Boezeman JB, Seyger MM, de Jong EM: Relevance of compartmentalization of T-cell subsets for clinical improvement in psoriasis: effect of immune-targeted antipsoriatic therapies. Br J Dermatol 2008; 159: 91-96.

- 6 Bos JD, de Rie MA, Teunissen MB, Piskin G: Psoriasis: dysregulation of innate immunity. Br J Dermatol 2005;152:1098-1107.
} 
7 Abrams JR, Kelley SL, Hayes E, Kikuchi T, Brown MJ, Kang S, Lebwohl MG, Guzzo CA, Jegasothy BV, Linsley PS, Krueger JG: Blockade of $\mathrm{T}$ lymphocyte costimulation with cytotoxic T lymphocyte-associated antigen 4-immunoglobulin (CTLA4Ig) reverses the cellular pathology of psoriatic plaques, including the activation of keratinocytes, dendritic cells, and endothelial cells. J Exp Med 2000;192:681-694.

8 Baker BS, Ovigne JM, Powles AV, Corcoran S, Fry L: Normal keratinocytes express Tolllike receptors (TLRs) 1,2 and 5: modulation of TLR expression in chronic plaque psoriasis. Br J Dermatol 2003;148:670-679.

9 de Jongh GJ, Zeeuwen PL, Kucharekova M, Pfundt R, van der Valk PG, Blokx W, Dogan A, Hiemstra PS, van de Kerkhof PC, Schalkwijk J: High expression levels of keratinocyte antimicrobial proteins in psoriasis compared with atopic dermatitis. J Invest Dermatol 2005; 125:1163-1173.

10 Gearing AJ, Fincham NJ, Bird CR, Wadhwa M, Meager A, Cartwright JE, Camp RD: Cytokines in skin lesions of psoriasis. Cytokine 1990;2:68-75.

11 Harder J, Schroder JM: Psoriatic scales: a promising source for the isolation of human skin-derived antimicrobial proteins. J Leukoc Biol 2005;77:476-486.

12 Jablonska S: Immunological mechanisms in psoriasis: role of polymorphonuclear leucocytes; in Farber EM, Nall L, Morhenn V, Jacobs PH (eds): Psoriasis. New York, Elsevier, 2007, p 1479.

13 Nickoloff BJ: Keratinocytes regain momentum as instigators of cutaneous inflammation. Trends Mol Med 2006;12:102-106.

$\checkmark 14$ Nickoloff BJ, Wrone-Smith T, Bonish B, Porcelli SA: Response of murine and normal human skin to injection of allogeneic bloodderived psoriatic immunocytes: detection of $T$ cells expressing receptors typically present on natural killer cells, including CD94, CD158, and CD161. Arch Dermatol 1999; 135:546-552.

15 Teunissen MB, Piskin G, Res PC, de Groot M, Picavet DI, de Rie MA, Bos JD: State of the art in the immunopathogenesis of psoriasis. G Ital Dermatol Venereol 2007; 142:229-242.

16 Zhou X, Krueger JG, Kao MC, Lee E, Du F, Menter A, Wong WH, Bowcock AM: Novel mechanisms of T-cell and dendritic cell activation revealed by profiling of psoriasis on the 63,100-element oligonucleotide array. Physiol Genomics 2003;13:69-78.

17 Gordon KB, Langley RG, Leonardi C, Toth D, Menter MA, Kang S, Heffernan M, Miller B, Hamlin R, Lim L, Zhong J, Hoffman R, Okun MM: Clinical response to adalimumab treatment in patients with moderate to severe psoriasis: double-blind, randomized controlled trial and open-label extension study. J Am Acad Dermatol 2006;55:598-606.
18 Leonardi CL, Powers JL, Matheson RT, Goffe BS, Zitnik R, Wang A, Gottlieb AB: Etanercept as monotherapy in patients with psoriasis. N Engl J Med 2003;349:2014-2022.

19 Reich K, Nestle FO, Papp K, Ortonne JP, Evans R, Guzzo C, Li S, Dooley LT, Griffiths CE: Infliximab induction and maintenance therapy for moderate-to-severe psoriasis: a phase III, multicentre, double-blind trial. Lancet 2005;366:1367-1374.

20 Tracey D, Klareskog L, Sasso EH, Salfeld JG, Tak PP: Tumor necrosis factor antagonist mechanisms of action: a comprehensive review. Pharmacol Ther 2008;117:244-279.

21 de Groot M, Teunissen MB, Picavet DI, de Rie MA, Bos JD: Reduction of different inflammatory cell types of the innate immune system in psoriatic skin during etanercept treatment. Exp Dermatol 2010;19:754-756.

22 Menter A, Tyring SK, Gordon K, Kimball $A B$, Leonardi CL, Langley RG, Strober BE, Kaul M, Gu Y, Okun M, Papp K: Adalimumab therapy for moderate to severe psoriasis: a randomized, controlled phase III trial. J Am Acad Dermatol 2008;58:106-115.

23 Saurat JH, Stingl G, Dubertret L, Papp K, Langley RG, Ortonne JP, Unnebrink K, Kaul M, Camez A: Efficacy and safety results from the randomized controlled comparative study of adalimumab vs. methotrexate vs. placebo in patients with psoriasis (CHAMPION). Br J Dermatol 2008;158:558-566.

24 van Kuijk AW, Gerlag DM, Vos K, Wolbink G, de Groot M, de Rie MA, Zwinderman AH, Dijkmans BA, Tak PP: A prospective, randomised, placebo-controlled study to identify biomarkers associated with active treatment in psoriatic arthritis: effects of adalimumab treatment on synovial tissue. Ann Rheum Dis 2009;68:1303-1309.

25 Conover WJ, Iman RL: Analysis of covariance using the rank transformation. Biometrics 1982;38:715-724.

26 van Lingen RG, de Jong EM, Berends MA, Seyger MM, van Erp PE, van de Kerkhof PC: Good clinical response to anti-psoriatic treatment with adalimumab and methotrexate does not inflict a direct effect on compartmentalization of T-cell subsets: a pilot study. J Dermatolog Treat 2008;19:284-287.

27 Bonish B, Jullien D, Dutronc Y, Huang BB, Modlin R, Spada FM, Porcelli SA, Nickoloff $\mathrm{BJ}$ : Overexpression of CD1d by keratinocytes in psoriasis and CD1d-dependent IFN-gamma production by NK-T cells. J Immunol 2000;165:4076-4085.
28 Nickoloff BJ, Bonish B, Huang BB, Porcelli SA: Characterization of a $\mathrm{T}$ cell line bearing natural killer receptors and capable of creating psoriasis in a SCID mouse model system. J Dermatol Sci 2000;24:212-225.

29 Cosmi L, de Palma R, Santarlasci V, Maggi L, Capone M, Frosali F, Rodolico G, Querci V, Abbate G, Angeli R, Berrino L, Fambrini M, Caproni M, Tonelli F, Lazzeri E, Parronchi P, Liotta F, Maggi E, Romagnani S, Annunziato F: Human interleukin 17-producing cells originate from a CD161+CD4+ T cell precursor. J Exp Med 2008;205:1903-1916.

30 Hueber W, Patel DD, Dryja T, Wright AM, Koroleva I, Bruin G, Antoni C, Draelos Z, Gold MH, Durez P, Tak PP, Gomez-Reino JJ, Foster CS, Kim RY, Samson CM, Falk NS, Chu DS, Callanan D, Nguyen QD, Rose K, Haider A, Di Padova F: Effects of AIN457, a fully human antibody to interleukin-17A, on psoriasis, rheumatoid arthritis, and uveitis. Sci Transl Med 2010;2:52ra72.

- 31 Di Cesare A, Di Meglio P, Nestle FO: The IL-23/Th17 axis in the immunopathogenesis of psoriasis. J Invest Dermatol 2009;129: 1339-1350.

32 Ohlsson K, Olsson I, Spitznagel K: Localization of chymotrypsin-like cationic protein, collagenase and elastase in azurophil granules of human neutrophilic polymorphonuclear leukocytes. Hoppe Seylers Z Physiol Chem 1977;358:361-366.

33 Meyer-Hoffert U, Wingertszahn J, Wiedow O: Human leukocyte elastase induces keratinocyte proliferation by epidermal growth factor receptor activation. J Invest Dermatol 2004;123:338-345.

34 Wiedow O, Wiese F, Streit V, Kalm C, Christophers E: Lesional elastase activity in psoriasis, contact dermatitis, and atopic dermatitis. J Invest Dermatol 1992;99:306-309.

-35 Wiedow O, Wiese F, Christophers E: Lesional elastase activity in psoriasis. Diagnostic and prognostic significance. Arch Dermatol Res 1995;287:632-635.

36 Chen GS, Wu TM, Yang SA, Yu HS: Quantitative assessments of physiological and biological parameters in psoriatic lesions and its correlations to the clinical severity of psoriasis. Kaohsiung J Med Sci 2001;17:408-418.

37 de Vlam K, Gottlieb AB, Fitzgerald O: Biological biomarkers in psoriatic disease. A review. J Rheumatol 2008;35:1443-1448.

38 Gottlieb A, Korman NJ, Gordon KB, Feldman SR, Lebwohl M, Koo JY, Van Voorhees AS, Elmets CA, Leonardi CL, Beutner KR, Bhushan R, Menter A: Guidelines of care for the management of psoriasis and psoriatic arthritis. Section 2. Psoriatic arthritis: overview and guidelines of care for treatment with an emphasis on the biologics. J Am Acad Dermatol 2008;58:851-864
Biomarkers Associated with Active Treatment in Psoriatic Arthritis
Dermatology 2012;225:298-303 DOI: $10.1159 / 000343290$ 